\title{
Selective Catalytic Reduction of NO by Cerium-based Metal- organic Frameworks
}

Received 00th January 20xx Accepted 00th January 20xx

DOI: $10.1039 / x 0 x \times 00000 x$

\author{
Simon Smolders, ${ }^{\mathrm{a}}$ Jannick Jacobsen, ${ }^{\mathrm{b}}$ Norbert Stock ${ }^{\mathrm{b}}$ and Dirk De Vos*c
}

Cerium oxide clusters have been incorporated in a porous metalorganic framework to increase their activity for the selective catalytic reduction (SCR) of $\mathrm{NO}$ with $\mathrm{NH}_{3}$. In addition, a new set of bimetallic MOFs, Ce $\mathrm{x} / \mathrm{Zr}$-CAU-24, was synthesized to further enhance the acid properties and thus increase the SCR activity of the cerium sites.

Nitrogen oxides $\left(\mathrm{NO}_{x}\right.$, i.e. $\mathrm{NO}$ and $\mathrm{NO}_{2}$, and $\left.\mathrm{N}_{2} \mathrm{O}\right)$ are major air pollutants that contribute to photochemical smog, acid rain, ozone depletion and the greenhouse effect. ${ }^{1}$ They are mainly emitted by power plants and automobiles; increasingly stringent legislation imposes effective $\mathrm{NO}_{x}$ removal, which can be achieved via the selective catalytic reduction (SCR) with $\mathrm{NH}_{3}$. Generally, $\mathrm{NH}_{3}-\mathrm{SCR}$ requires a bifunctional catalyst, with both acidic and redox properties because the reaction mechanism is believed to consist of an acid cycle, in which ammonia is adsorbed, and a redox cycle that involves the oxidation of an $\mathrm{NH}_{3}$ or $\mathrm{NO}$ derived species. ${ }^{2}$ Finally, an intermediate with an $\mathrm{N}$ $\mathrm{N}$ bond is formed, which decomposes to $\mathrm{N}_{2}$ and $\mathrm{H}_{2} \mathrm{O}$. The catalytic cycle is closed by reoxidation of the redox site, which requires oxygen in the standard $\mathrm{NH}_{3}$-SCR reaction (reaction 1 ). However, the reaction can also proceed under anoxic conditions when sufficient $\mathrm{NO}_{2}$ is present, which is called "fast" SCR (reaction 2). ${ }^{3}$ In addition, some side reactions are known, such as the formation of $\mathrm{N}_{2} \mathrm{O}$, an undesired strong greenhouse gas.

$4 \mathrm{NH}_{3}+4 \mathrm{NO}+\mathrm{O}_{2} \rightarrow 4 \mathrm{~N}_{2}+6 \mathrm{H}_{2} \mathrm{O}$ (standard SCR)

$4 \mathrm{NH}_{3}+2 \mathrm{NO}+2 \mathrm{NO}_{2} \rightarrow 4 \mathrm{~N}_{2}+6 \mathrm{H}_{2} \mathrm{O}$ ("fast" SCR)

Conventional SCR catalysts include transition-metal exchanged zeolites and complex mixtures of metal oxides such as the $\mathrm{V}_{2} \mathrm{O}_{5}$

\footnotetext{
a. Centre for Membrane Separations, Adsorption, Catalysis and Spectroscopy for Sustainable Solutions, KU Leuven, Celestijnenlaan $200 \mathrm{~F}$ p.o. box 2454, 3001 Leuven, Belgium.E-mail: dirk.devos@kuleuven.be

b. Institut für Anorganische Chemie, Christian-Albrechts-Universität, Max-Eyth Strabe 2, 24118 Kiel, Germany

+ Footnotes relating to the title and/or authors should appear here.

Electronic Supplementary Information (ESI) available: [details of any supplementary information available should be included here]. See DOI: 10.1039/x0xx00000x
}

$\mathrm{WO}_{3} / \mathrm{TiO}_{2}$ catalyst. ${ }^{2,3}$ The toxicity of vanadium however calls for more environmentally friendly alternatives such as manganese oxide and ceria. ${ }^{4} \mathrm{CeO}_{2}$ is cheap and non-toxic but has been mainly investigated as SCR catalyst due to its excellent redox properties. ${ }^{5}$ It can easily switch between $\mathrm{Ce}^{4+}$ and $\mathrm{Ce}^{3+}$ resulting in very mobile oxygen atoms which can be stored and released (creating oxygen vacancies) via a redox change between the two oxidation states. Ceria is however in its pure form not a good $\mathrm{NH}_{3}$-SCR catalyst because of its inherently weak Lewis acidity; so enhancing the number of acid sites by increasing the catalysts' surface area is an interesting strategy. ${ }^{6}$ High surface area ceria is however hard to synthesize and very prone to sintering; hence alternative highly dispersed ceria catalysts should be developed. ${ }^{7}$

Metal-organic frameworks (MOFs) are potentially porous and crystalline materials built up by metal (oxide) nodes connected through organic linkers. ${ }^{8}$ Their large concentration of metal nodes, exceptionally high surface area and tunable pore size and metal content makes them particularly interesting for catalysis, gas storage and separation. ${ }^{9-11}$ Several MOFs, such as MOF-74(M) ( $\mathrm{M}=\mathrm{Cu}, \mathrm{Mn}, \mathrm{Co})$ and MIL-100(Fe), have already been reported for SCR but no Ce-MOFs have been studied, although they contain $\left[\mathrm{Ce}_{6} \mathrm{O}_{6}\right]^{12+}$ clusters that can act as ceria nanoparticles. ${ }^{12-16}$ In addition, these Ce-MOFs are isoreticular to Zr-based frameworks with well-studied Lewis acid sites which are present either as defects (UiO-66), or as open site on an intrinsically undercoordinated cluster (NU-1000 or CAU-24). ${ }^{17-}$ 19

Herein, we report the first $\mathrm{NH}_{3}-\mathrm{SCR}$ reaction catalyzed by the Ce-MOFs Ce-UiO-66 and Ce-CAU-24 and their bimetallic $\mathrm{Ce} / \mathrm{Zr}$ analogues. Ce-UiO-66 contains fully connected metal clusters in the ideal, defect-free framework, but the synthesized material has been reported with approximately one missing linker and thus one open site per cluster. ${ }^{12}$ The $\left[\mathrm{Ce}_{6} \mathrm{O}_{8}\right]^{8+}$ cluster in Ce-CAU24 is 8-fold connected; hence four open sites per secondary building unit are expected. ${ }^{19}$ For the relatively new group of CeMOFs, the SCR reaction is an excellent test case to explore the reversible redox behavior of the clusters; MOFs that intactly 
survive redox changes of their metal building blocks are relatively rare. ${ }^{13,20-22}$
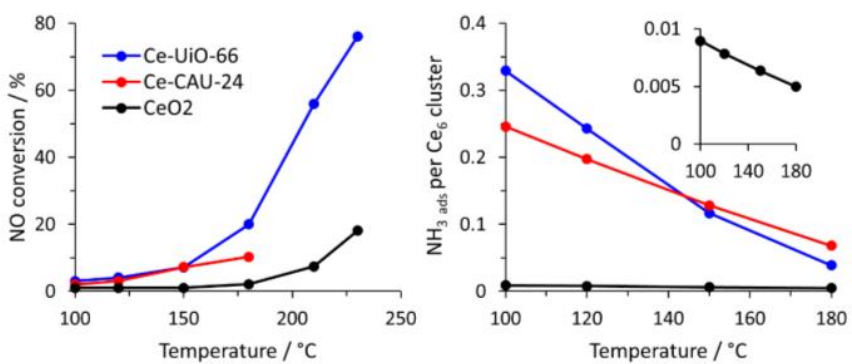

Fig. 1. Comparison of Ce-MOFs with ceria: NO conversion (left) and $\mathrm{NH}_{3}$ adsorption (right). The Ce-MOFs are tested up to their thermal stability limit. Reaction conditions: $[\mathrm{NO}]=\left[\mathrm{NH}_{3}\right]=500$ ppm, $\left[\mathrm{O}_{2}\right]=10 \% ; 30 \mathrm{ml} / \mathrm{min}\left(\mathrm{GHSV} \approx 9000 \mathrm{~h}^{-1}\right)$. Adsorption conditions: $\left[\mathrm{NH}_{3}\right]=500 \mathrm{ppm}$.

Both MOFs outperform the commercially available $\mathrm{CeO}_{2}$ catalyst and Ce-UiO-66 reaches significant NO decomposition at temperatures above $200^{\circ} \mathrm{C}$ (Fig. 1). Curiously, Ce-UiO-66 is more active than $\mathrm{Ce}-\mathrm{CAU}-24$, even though the latter should contain four times more open metal sites. Adsorption experiments in a $500 \mathrm{ppm} \mathrm{NH}_{3}$ stream at $100^{\circ} \mathrm{C}$ however reveal that only $1 / 16^{\text {th }}$ of the open sites in Ce-CAU-24 are occupied by $\mathrm{NH}_{3}$, thus featuring a lower adsorption capacity than Ce-UiO-66 $\left(1 / 3^{\text {rd }}\right.$ occupied). Both Ce-MOFs feature a much higher $\mathrm{NH}_{3}$ adsorption than ceria, but their relative loss in $\mathrm{NH}_{3}$ adsorption capacity with increasing temperature is larger, suggesting that Ce-MOFs contain relatively more weak acid sites. As a result, the CeMOFs' activities are, as for $\mathrm{CeO}_{2}$, very likely limited by their $\mathrm{NH}_{3}$ adsorption capacity. ${ }^{6}$ Their $\mathrm{N}_{2}$ selectivity however remains above $98 \%$ in the whole temperature range, indicating that the acidity is sufficient to avoid excessive overoxidation of $\mathrm{NH}_{3}$. Addition of $5 \%$ water to the gas mixture results in a reversible $30 \%$ activity drop of Ce-UiO-66 because its open metal sites render the material hydrophilic (Fig. S26).

The ammonia affinity of the Ce-MOFs could be improved by introducing the stronger Lewis acidic $\mathrm{Zr}^{4+}$ to the metal cluster. In addition, bimetallic $\mathrm{Ce} / \mathrm{Zr}$-MOFs can be operated in a broader temperature window because of their enhanced stability. ${ }^{23}$ $\mathrm{Ce} / \mathrm{Zr}$-UiO-66 has already been reported but there was so far no sufficiently stable $\mathrm{Ce} / \mathrm{Zr}-\mathrm{MOF}$ with an undercoordinated secondary building unit (SBU) known. Therefore, we developed the synthesis of a new series of Ce/Zr-MOFs with scu topology: $\mathrm{Ce}_{\mathrm{x}} / \mathrm{Zr}-\mathrm{CAU}-24$. Four materials with Ce:Zr ratio of 10:90 $\left(\mathrm{Ce}_{10} / \mathrm{Zr}-\right.$ CAU-24), 16:84 (Ce $\left.{ }_{16} / \mathrm{Zr}-\mathrm{CAU}-24\right), 29: 71$ (Ce $\left.29 / \mathrm{Zr}-\mathrm{CAU}-24\right)$ and 53:47 ( $\mathrm{Ce}_{53} / \mathrm{Zr}$-CAU-24) were synthesized (details in SI) and their phase purity was confirmed by powder X-ray diffraction (PXRD) (Fig. 2, S2-5)

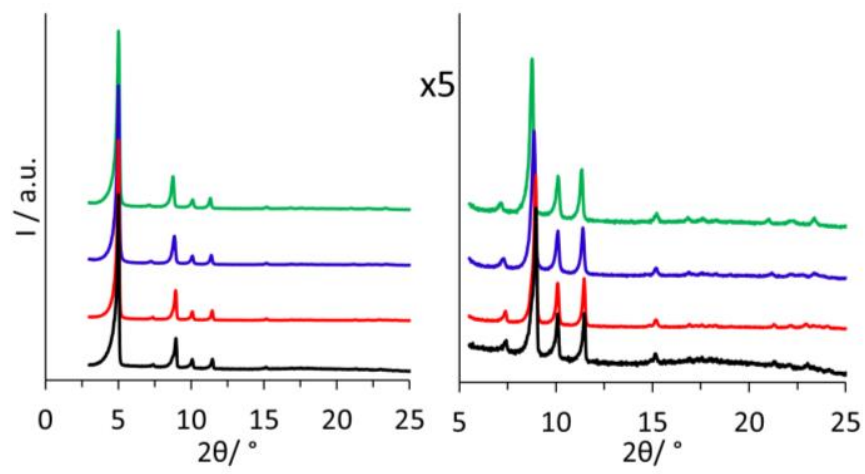

Fig. 2 PXRD patterns of the four new $\mathrm{Ce}_{x} / \mathrm{Zr}-\mathrm{CAU}-24$ MOFs with $x=53$ (top); 29 (top middle); 16 (bottom middle) and 10 (bottom). Right: 5 -fold zoom of $5-25^{\circ} 2 \theta$ region.

Similar to previously reported $\mathrm{Ce} / \mathrm{Zr}$-MOFs, the thermal stability of $\mathrm{Ce}_{\mathrm{x}} / \mathrm{Zr}$-CAU-24 strongly increases when the Ce:Zr ratio drops below 16:84, i.e. one Ce atom per cluster on average, which was demonstrated by $\mathrm{N}_{2}$-physisorption and PXRD after activation at $160^{\circ} \mathrm{C}$ (Fig. S7-8). ${ }^{23}$ Furthermore, thermogravimetric analysis revealed that $\mathrm{Ce}_{\mathrm{x}} / \mathrm{Zr}$-CAU-24 with a Ce:Zr ratio above 10:90 contains missing clusters, a defect type which, in contrast to missing linkers, decreases the number of open metal sites, and thus the SCR activity (Fig. S9-12). ${ }^{24}$ Therefore, only $\mathrm{Ce}_{10} / \mathrm{Zr}$-CAU24 and $\mathrm{Ce}_{10} / \mathrm{Zr}$-UiO-66, which contain $\mathrm{Zr}_{6}$ and $\mathrm{Zr}_{5} \mathrm{Ce}$ clusters, are compared to physical mixtures of $\mathrm{Ce}$-and $\mathrm{Zr}$-MOFs, denoted as Ce-UiO-66/Zr-UiO-66 and Ce-CAU-24/Zr-CAU-24, with the same metal ratio (Fig. 3). ${ }^{25,26}$
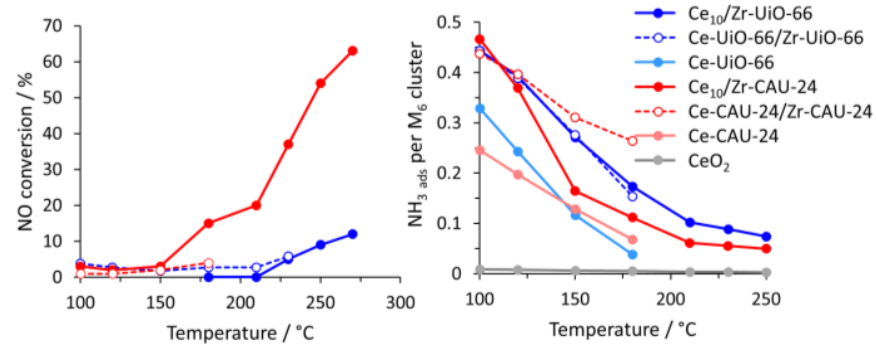

Fig. 3 Comparison of $\mathrm{Ce}_{10} / \mathrm{Zr}-\mathrm{MOFs}$ with physical Ce-MOF/ZrMOF mixtures: $\mathrm{NO}$ conversion (left) and $\mathrm{NH}_{3}$ adsorption (right). The MOFs are tested up to their thermal stability limit. The $\mathrm{NH}_{3}$ adsorption of the all-Ce catalysts is also displayed as reference. Reaction conditions: $[\mathrm{NO}]=\left[\mathrm{NH}_{3}\right]=500 \mathrm{ppm},\left[\mathrm{O}_{2}\right]=10 \% ; 30$ $\mathrm{ml} / \mathrm{min}\left(\mathrm{GHSV} \approx 9000 \mathrm{~h}^{-1}\right.$ ). Adsorption conditions: $\left[\mathrm{NH}_{3}\right]=500$ ppm.

The mixed metal MOFs indeed feature a higher $\mathrm{NH}_{3}$ adsorption capacity than their all-Ce analogues, demonstrating that their open sites are on average more acidic by virtue of the stronger Lewis acid zirconium. Furthermore, the nearly identical adsorption behavior of $\mathrm{Ce}_{10} / \mathrm{Zr}$-UiO-66 and Ce-UiO-66/Zr-UiO66 suggests that the vicinity of the two metals does not influence the overall adsorption. However, $\mathrm{Ce}_{10} / \mathrm{Zr}$-CAU-24 features a lower ammonia adsorption at elevated temperatures than Ce-CAU-24/Zr-CAU-24. This can be rationalized by the 
likely preferential location of the $\mathrm{Ce}$ atom in equatorial plane of the $\mathrm{Zr}_{5} \mathrm{Ce}$ cluster of $\mathrm{Ce}_{10} / \mathrm{Zr}-\mathrm{CAU}-24$, as has already been described for Ce/Zr-CAU-38 (Fig.4). ${ }^{26}$ The open metal sites of CAU-24 are situated in this equatorial plane, resulting in a higher Ce:Zr ratio in the accessible adsorption sites of $\mathrm{Ce}_{10} / \mathrm{Zr}$ CAU-24 and thus a decreased ammonia affinity.

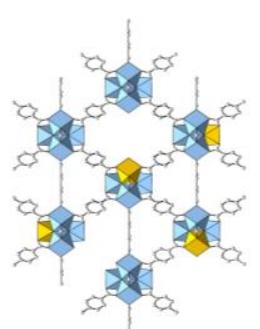

UiO-66
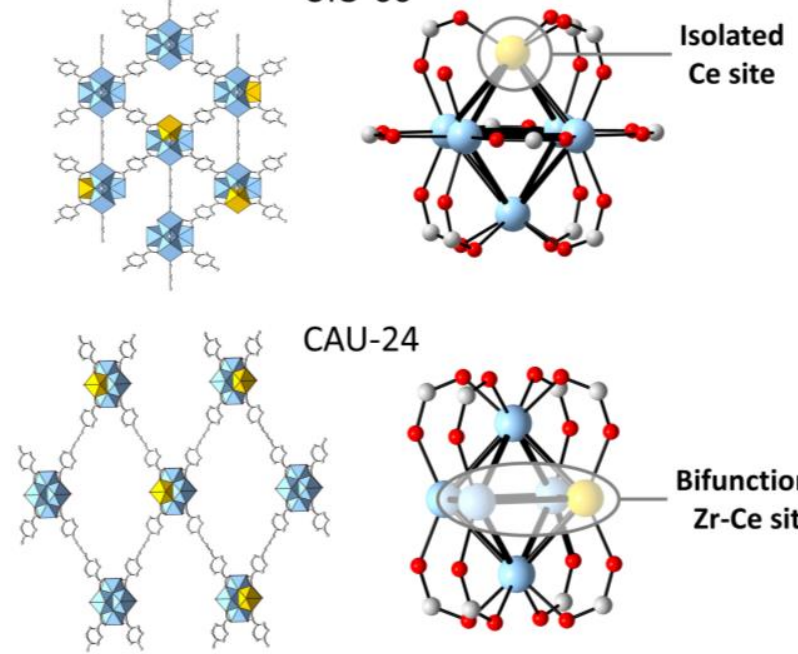

CAU-24

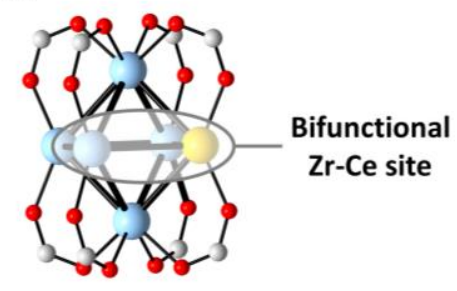

Fig. 4 Schematic representation of $\mathrm{Ce}_{10} / \mathrm{Zr}$-UiO- 66 with random missing linker defects (top) and $\mathrm{Ce}_{10} / \mathrm{Zr}$-CAU-24 (bottom) and their $\mathrm{Zr}_{5} \mathrm{Ce}$ clusters (right). $\mathrm{Zr}=$ blue, $\mathrm{Ce}=$ yellow, $\mathrm{O}=$ red, $\mathrm{C}=$ gray, cluster $\mu_{3}$-oxygen and hydrogen atoms are omitted for clarity.

The tenfold dilution of redox active sites by zirconium results in a lower SCR activity (per mol catalyst) of $\mathrm{Ce}_{10} / \mathrm{Zr}$-UiO-66 and CeUiO-66/Zr-UiO-66 compared to the all-Ce UiO-66 material. However, $\mathrm{Ce}_{10} / \mathrm{Zr}$-CAU-24 is above $150^{\circ} \mathrm{C}$ more active than CeCAU-24. This apparent discrepancy can be understood based on the need for a bifunctional catalyst: the stronger affinity of $\mathrm{NH}_{3}$ for open Zr sites only improves the SCR activity if there is a nearby open Ce site, which is unlikely in $\mathrm{Ce}_{10} / \mathrm{Zr}$-UiO-66 because it on average contains only one open site (either $\mathrm{Zr}$ or Ce) per cluster. In contrast, every Ce site in $\mathrm{Ce}_{10} / \mathrm{Zr}$-CAU-24 is likely coordinatively unsaturated and has two neighboring open $\mathrm{Zr}$ sites which are sufficiently acidic, resulting in a greatly improved activity of the Ce ion.

The reaction orders of $\mathrm{NO}(1), \mathrm{NH}_{3}(0)$ and $\mathrm{O}_{2}(0.07)$ over ceria are in accordance to literature and the absence of NO adsorption suggests an Eley-Rideal mechanism in which ammonia is first adsorbed and subsequently reacts with gaseous $\mathrm{NO}_{x}$ species to form $\mathrm{N}_{2}$ (Fig. 5 and S23). ${ }^{27}$ Similarly, the NO reaction order is 1 on Ce-UiO-66 and $\mathrm{Ce}_{10} / \mathrm{Zr}-\mathrm{CAU}-24$ and NO adsorption is not observed (Fig. S24-25), suggesting that NO reacts from the gas phase. Remarkably, the $\mathrm{NH}_{3}$ order is 0.25 on Ce-UiO-66 and ammonia adsorption is observed, confirming that the MOF's acidic adsorption sites are relatively weak. The ammonia order on $\mathrm{Ce}_{10} / \mathrm{Zr}$-CAU-24 is only 0.11 , demonstrating the increased acidity of the bimetallic MOF. Ce-MOFs are known to solely undergo one-electron redox reactions so reoxidation cannot occur through the conventional oxygen vacancy mechanism. ${ }^{13}$ Consequently, the oxygen order on Ce-UiO-66 (0.20) and $\mathrm{Ce}_{10} / \mathrm{Zr}-\mathrm{CAU}-24$ (0.17) are slightly higher than on ceria but the exact interaction between oxygen and $\mathrm{Ce}^{3+}$ in the MOFs remains unclear.

Conversion in absence of one reactant can provide meaningful insights in the reaction mechanism (reaction conditions: $210^{\circ} \mathrm{C}$; $\mathrm{N}_{2}$ balance gas; $150 \mathrm{ml} / \mathrm{min} ; 1000 \mathrm{mg} \mathrm{CeO}$ or $200 \mathrm{mg} \mathrm{Ce-UiO-}$ 66). When a $500 \mathrm{ppm} \mathrm{NH}+10 \% \mathrm{O}_{2}$ flow is sent over a ceria bed, no nitrogen oxides are formed nor is any ammonia conversion observed. Ce-UiO-66 however converts $10 \mathrm{ppm} \mathrm{NH}$ but only 1 ppm NO and $0.1 \mathrm{ppm} \mathrm{N}_{2} \mathrm{O}$ are observed the reactor outlet, suggesting that $\mathrm{NH}_{3}$ is mainly converted to $\mathrm{N}_{2}$ by first oxidizing to $\mathrm{NO}_{x}$, followed by reaction with another $\mathrm{NH}_{3}$ molecule. The overoxidation of $\mathrm{NH}_{3}$ could be rationalized by the weak acid site strength of Ce-UiO-66, meaning that the $\mathrm{NH}_{3}$ is free to react, rather than being adsorbed on an acid site.

Under a $500 \mathrm{ppm} \mathrm{NO}+500 \mathrm{ppm} \mathrm{NH}_{3}$ flow in absence of $\mathrm{O}_{2}$, ceria converts approximately $23 \mathrm{ppm}$ of NO, likely due to the stoichiometric generation of oxygen vacancies on the surface. In contrast, $\mathrm{Ce}-\mathrm{UiO}-66$ only converts $5 \mathrm{ppm}$, thereby indicating that stoichiometric reduction of Ce-MOFs is much harder, likely due to their inability to contain oxygen vacancies.

Based on literature reports and the above findings, we can suggest a simplified $\mathrm{E}-\mathrm{R}$ reaction mechanism for both ceria and Ce-MOFs:

$$
\begin{gathered}
\mathrm{NH}_{3} \rightarrow \mathrm{NH}_{3 a d s} \\
\mathrm{NH}_{3 \text { ads }}+\mathrm{Ce}^{4+} \rightarrow \mathrm{NH}_{2 a d s}+\mathrm{Ce}^{3+}+\mathrm{H}^{+} \\
\mathrm{NH}_{2 a d s}+\mathrm{NO} \rightarrow \mathrm{N}_{2}+\mathrm{H}_{2} \mathrm{O} \\
\mathrm{Ce}^{3+}+\mathrm{H}^{+}+\frac{1}{4} \mathrm{O}_{2} \rightarrow \mathrm{Ce}^{4+}+\frac{1}{2} \mathrm{H}_{2} \mathrm{O}
\end{gathered}
$$

Ammonia is herein first adsorbed on an acid site and subsequently subjected to hydrogen abstraction. The oxidized $\mathrm{NH}_{2 \text { ads }}$ species then reacts with gaseous $\mathrm{NO}$ and decomposes to $\mathrm{N}_{2}$ and water. At last, the $\mathrm{Ce}^{3+}$ is reoxidized by oxygen. The slightly different behavior of Ce-MOFs compared to ceria can be attributed to the number and strength of the acid sites and the ability to generate oxygen vacancies in $\mathrm{CeO}_{2}$.

\section{Conclusions}

In conclusion, two Ce-MOFs, Ce-UiO-66 and Ce-CAU-24, were tested as $\mathrm{NH}_{3}-\mathrm{SCR}$ catalysts. They both outperform ceria because they feature a higher number of acid sites on which ammonia can be adsorbed. The acid strength of Ce-MOFs is believed to limit their activity; hence a new series of mixedmetal Ce/Zr-MOFs, denoted Ce $\mathrm{C}_{\mathrm{x}} / \mathrm{Zr}-\mathrm{CAU}-24$, was developed. The thermally stable bimetallic $\mathrm{Ce}_{10} / \mathrm{Zr}$-CAU-24 with $\mathrm{Zr}_{5} \mathrm{Ce}$ clusters features redox-active Ce sites surrounded by strongly acidic open $\mathrm{Zr}$ sites, resulting in a higher SCR activity than for Ce-CAU-24, irrespective of its much lower $\mathrm{Ce}$ content. Reoxidation of the MOF catalysts may however be hampered by their lack of oxygen vacancies, hence future research should focus on the synthesis of MOFs with bimetallic Ce/Zr SBUs that allow the creation of oxygen vacancies, while maintaining sufficiently acidic sites. 

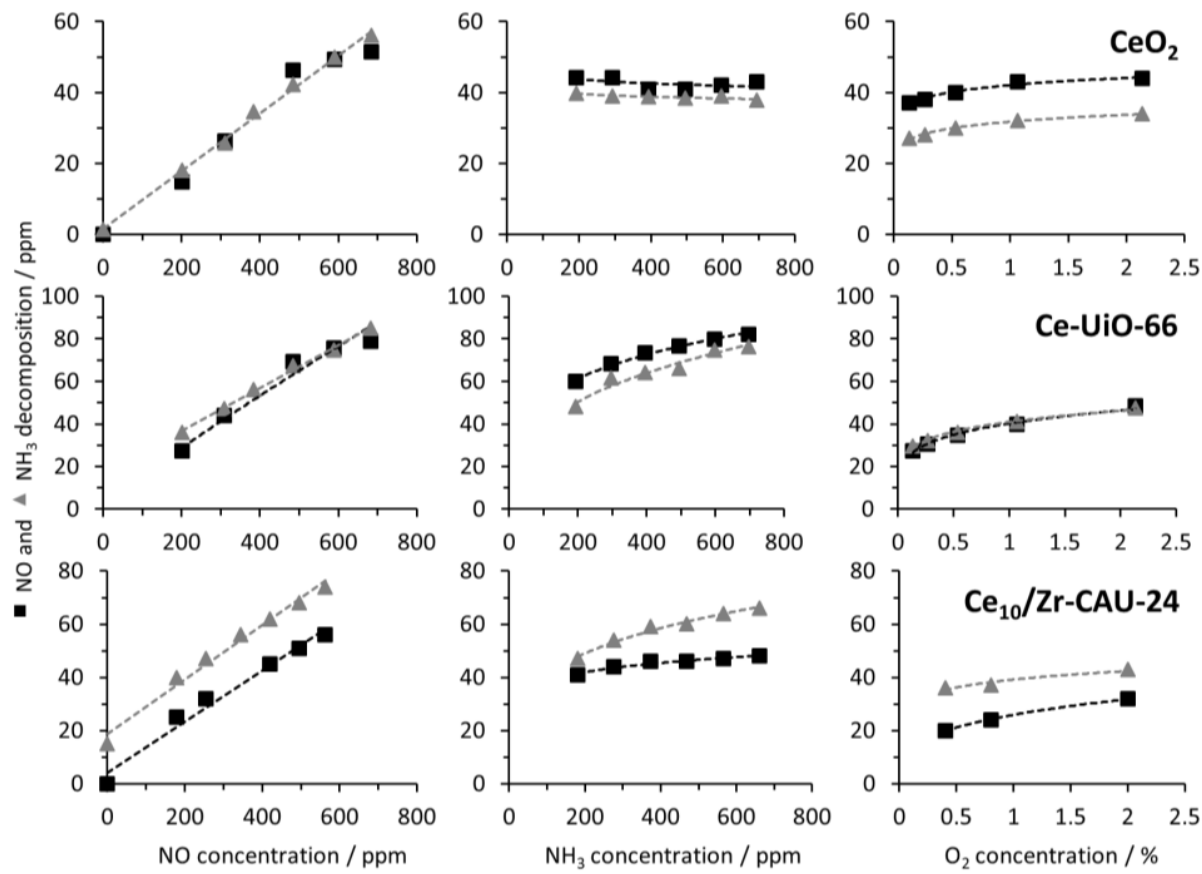

Fig. 5 Absolute $\mathrm{NO}$ and $\mathrm{NH}_{3}$ decomposition (in ppm's) as function of a variable $\mathrm{NO}$ (left), $\mathrm{NH}_{3}$ (middle) and $\mathrm{O}_{2}$ (right) inlet concentration over ceria (top), Ce-UiO-66 (middle) and $\mathrm{Ce}_{10} / \mathrm{Zr}-\mathrm{CAU}-24$ (bottom). Reaction conditions: $210^{\circ} \mathrm{C}$; [NO] $=500 \mathrm{ppm}$, $\left[\mathrm{NH}_{3}\right]=500 \mathrm{ppm},\left[\mathrm{O}_{2}\right]=10 \% ; 1000 \mathrm{mg} \mathrm{CeO}$ or $200 \mathrm{mg} \mathrm{MOF}$

\section{Conflicts of interest}

There are no conflicts to declare.

\section{Acknowledgements}

S.S. and D.D.V. gratefully acknowledge the FWO for funding (Aspirant grant and project funding).

\section{Notes and references}

1 J. Yu, Z. Si, L. Chen, X. Wu and D. Weng, Appl. Catal. B Environ., 2015, 163, 223-232.

N. Topsoe, Science (80-. )., 1994, 265, 1217-1219.

T. V. W. Janssens, H. Falsig, L. F. Lundegaard, P. N. R. Vennestrøm, S. B. Rasmussen, P. G. Moses, F. Giordanino, E. Borfecchia, K. A. Lomachenko, C. Lamberti, S. Bordiga, A. Godiksen, S. Mossin and P. Beato, ACS Catal., 2015, 5, 2832-2845.

G. Qi, R. T. Yang and R. Chang, Appl. Catal. B Environ, 2004, 51 , 93-106.

5 T. Gu, Y. Liu, X. Weng, H. Wang and Z. Wu, Catal. Commun., 2010, 12, 310-313.

6 C. Tang, H. Zhang and L. Dong, Catal. Sci. Technol., 2016, 6, 12481264

7 W. Shan, F. Liu, Y. Yu and H. He, Cuihua Xuebao/Chinese J. Catal., 2014, 35, 1251-1259.

8 H. Furukawa, K. E. Cordova, M. O'Keeffe and O. M. Yaghi, Science (80-. )., 2013, 341, 1230444-1230444.

9 S. M. J. Rogge, A. Bavykina, J. Hajek, H. Garcia, A. I. Olivos-Suarez, A. Sepúlveda-Escribano, A. Vimont, G. Clet, P. Bazin, F. Kapteijn, M. Daturi, E. V Ramos-Fernandez, F. X. i Xamena, V. Van Speybroeck and J. Gascon, Chem. Soc. Rev., 2017, 46, 3134-3184.

10 S. Ma and H.-C. Zhou, Chem. Commun., 2010, 46, 44-53.

11 J. R. Li, J. Sculley and H. C. Zhou, Chem. Rev., 2012, 112, 869-932.

12 M. Lammert, M. T. Wharmby, S. Smolders, B. Bueken, A. Lieb, K. A. Lomachenko, D. De Vos and N. Stock, Chem. Commun., 2015, 51, 12578-12581.
C. Atzori, N. Stock, C. Lamberti, M. B. J. Roeffaers and D. E. De Vos, ChemPhysChem, 2018, 19, 373-378.

14 H. Jiang, Q. Wang, H. Wang, Y. Chen and M. Zhang, ACS Appl. Mater. Interfaces, 2016, 8, 26817-26826. Chem. Res., 2017, 56, 3542-3550.

P. Wang, H. Zhao, H. Sun, H. Yu, S. chen and X. Quan, RSC Adv. 2014, 4, 48912-48919.

17 F. Vermoortele, B. Bueken, G. Le Bars, B. Van de Voorde, M. Vandichel, K. Houthoofd, A. Vimont, M. Daturi, M. Waroquier, V. Van Speybroeck, C. Kirschhock and D. E. De Vos, J. Am. Chem. Soc., 2013, 135, 11465-11468.

S. Y. Moon, Y. Liu, J. T. Hupp and O. K. Farha, Angew. Chemie - Int Ed., 2015, 66, 6795-6799.

19 M. Lammert, H. Reinsch, C. A. Murray, M. T. Wharmby, H. Terraschke and N. Stock, Dalt. Trans., 2016, 45, 18822-18826.

J. W. Yoon, Y. K. Seo, Y. K. Hwang, J. S. Chang, H. Leclerc, S. Wuttke, P. Bazin, A. Vimont, M. Daturi, E. Bloch, P. L. Llewellyn, C. Serre, P. Horcajada, J. M. Grenèche, A. E. Rodrigues and G. Férey, Angew. Chemie - Int. Ed., 2010, 49, 5949-5952.

B. Bueken, F. Vermoortele, D. E. P. Vanpoucke, H. Reinsch, C.-C. Tsou, P. Valvekens, T. De Baerdemaeker, R. Ameloot, C. E. A. Kirschhock, V. Van Speybroeck, J. M. Mayer and D. De Vos, Angew. Chemie Int. Ed., 2015, 54, 13912-13917.

S. Smolders, T. Willhammar, A. Krajnc, K. Sentosun, M. T. Wharmby, K. A. Lomachenko, S. Bals, G. Mali, M. B. J. Roeffaers, D. E. De Vos and B. Bueken, Angew. Chemie, 2019, 131, 9258-9263. M. Lammert, C. Glißmann and N. Stock, Dalt. Trans., 2017, 46, 2425-2429.

24 M. J. Cliffe, W. Wan, X. Zou, P. A. Chater, A. K. Kleppe, M. G. Tucker, H. Wilhelm, N. P. Funnell, F.-X. Coudert and A. L. Goodwin, Nat. Commun., 2014, 5, 4176.

K. A. Lomachenko, J. Jacobsen, A. L. Bugaev, C. Atzori, F. Bonino, S. Bordiga, N. Stock and C. Lamberti, J. Am. Chem. Soc., 2018, 140, 17379-17383. 12820-12826. 